Annales Geophysicae (2001) 19: 341-349 (C) European Geophysical Society 2001

\title{
F2-layer parameters long-term trends at the Argentine Islands and Port Stanley stations
}

\author{
A. D. Danilov ${ }^{1}$ and A. V. Mikhailov ${ }^{2}$ \\ ${ }^{1}$ Institute of Applied Geophysics, Rostokinskaya 9, Moscow 129128, Russia \\ ${ }^{2}$ Institute of Terrestrial Magnetism, Ionosphere and Radio Wave Propagation, Troitsk, Moscow Region 142190, Russia
}

Received: 18 September 2000 - Revised: 9 January 2001 - Accepted: 14 February 2001

\begin{abstract}
The ionospheric sounding data at two southern hemisphere stations, the Argentine Islands and Port Stanley, are analyzed using a method previously developed by the authors. Negative trends of the critical frequency $f_{o} \mathrm{~F} 2$ are found for both stations. The magnitudes of the trends are close to those at the corresponding (close geomagnetic latitude) stations of the northern hemisphere, as considered previously by the authors. The values of the F2 layer height $h m \mathrm{~F} 2$ absolute trends $\Delta h m \mathrm{~F} 2$ are considered. The effect of $\Delta h m \mathrm{~F} 2$ dependence on $h m \mathrm{~F} 2$ found by Jarvis et al. (1998) is reproduced. A concept is considered that long-term changes of the geomagnetic activity may be an important (if not the only) cause of all the trends of $f o \mathrm{~F} 2$ and $h m \mathrm{~F} 2$ derived by several groups of authors. The dependence of both parameters on the geomagnetic index $A p$ corresponds to a smooth scheme of the ionospheric storm physics and morphology; thus, a principal cause of the $f o \mathrm{~F} 2$ and $h m \mathrm{~F} 2$ geomagnetic trends is most probably a trend found in several publications in the number and intensity of ionospheric storms.
\end{abstract}

Key words. Ionosphere (ionosphere-atmosphere interaction; ionospheric disturbances)

\section{Introduction}

The problem of long-term (longer that one solar cycle) changes in the upper atmosphere and ionosphere has attracted interest in recent years (see the reviews by Danilov, 1997, 1998). Several scientific groups tried various approaches and various sets of data to look for long-term changes (trends) of various parameters. Routine ionospheric observations present a wide field for such studies, and several authors (Bencze et al., 1998; Bremer, 1996, 1998; Danilov and Mikhailov, 1998, 1999a, b; Givishvili and Leshchenko, 1993, 1994; Jarvis et al., 1998, Ulich and Turunen, 1997; Ulich et al., 1997; Upadhyay and Mahajan, 1998) attempted to search for trends in the ionospheric parameters, considering the F2 layer first.

Correspondence to: A. D. Danilov (danilov@wdcb.rssi.ru)
Jarvis et al. (1998) considered in detail values of the F2 layer peak altitude $h m \mathrm{~F} 2$ obtained by vertical sounding at two southern hemisphere stations: Argentine Islands and Port Stanley. They applied the method of trend determination used by Bremer (1988). The most essential point of the method is that the trend is taken as an absolute difference between the observed and the given by model values of $h m \mathrm{~F} 2$. The model describes the $h m \mathrm{~F} 2$ dependence on solar activity (sunspot number $R$ or radiowave flux at $10.7 \mathrm{~cm}, F_{10.7}$ ), as well as the $h m \mathrm{~F} 2$ dependence on geomagnetic activity ( $A p$ index).

The principal result of Jarvis et al. (1998) was that a negative trend of $h m \mathrm{~F} 2$ was found for both stations under consideration. It qualitatively agrees with the predictions of Rishbeth (1990), but the amplitude of the negative trend obtained is much higher than that predicted. Jarvis et al. (1998) found, in addition, that the altitude trend $\Delta h m \mathrm{~F} 2$ depends on the altitude itself; the value of the negative trend is larger for higher altitudes.

Danilov and Mikhailov (1998) suggested a new approach to derive long-term trends of the $\mathrm{F} 2$ region parameters. Using this approach, Danilov and Mikhailov (1999a, b) analyzed the data set from the northern hemisphere stations and obtained a consistent picture of the $f o \mathrm{~F} 2$ trend which varyed in a systematic way with local time, season, and geomagnetic latitude.

In this paper, an attempt is made to apply the above mentioned approach to the data from the two stations considered by Jarvis et al. (1998) and to compare the conclusions.

\section{Long-term changes}

The method proposed by Danilov and Mikhailov (1998) and used by Danilov and Mikhailov (1999a, b) and Mikhailov and Marin (2000) considers relative deviations of the parameters analyzed from a model:

$\delta f o \mathrm{~F} 2=\left(f o \mathrm{~F} 2_{\mathrm{obs}}-f o \mathrm{~F} 2_{\mathrm{mod}}\right) / f o \mathrm{~F} 2_{\mathrm{mod}}$

$\delta h m \mathrm{~F} 2=\left(h m \mathrm{~F} 2_{\text {obs }}-h m \mathrm{~F} 2_{\text {mod }}\right) / h m \mathrm{~F} 2_{\text {mod }}$ 


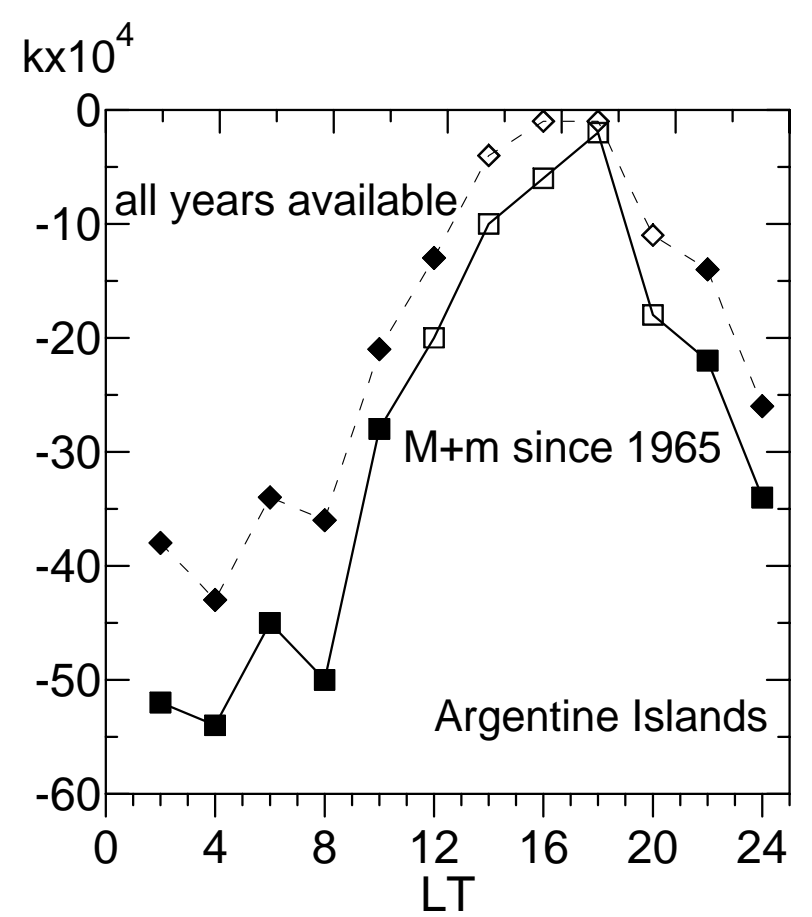

Fig. 1. Value of the $f o \mathrm{~F} 2$ trend $k$ at the Argentine Islands versus local time. Filled diamonds and rectangles show the data significant at the 95\% level, according to the Fisher criterion, except for the 0000-1000 LT interval for all years (diamonds) where the points have a $99 \%$ significance. Open symbols correspond to statistically insignificant data at the confidence level chosen.

The main advantage of the method is that, contrary to the method in which the absolute values are used, it is possible to use the long-term changes of the parameters in various LT moments and months, in spite of the strong diurnal and seasonal variations of both $f o \mathrm{~F} 2$ and $h m \mathrm{~F} 2$. The third degreepolynomial, in respect to the sunspot number $R_{12}$, was used as a model. By using data from 22 stations of the global ionospheric network and considering only the years of solar cycle minima and maxima, the trend in $f o \mathrm{~F} 2$ was found to be negative for all stations (e.g. Danilov and Mikhailov, 1999). More information on the method and results for various stations can be found in the above references.

To analyze the trends at the Argentine Islands and Port Stanley stations we used the same method. The data on $f o \mathrm{~F} 2$ were taken from the WDCC1/UK site on the Internet, and the data on $h m \mathrm{~F} 2$ were kindly presented to us by Martin Jarvis. According to Jarvis et al. (1998), in order to derive $h m \mathrm{~F} 2$ values from the M3000 parameter, they have used the wellknown Bradley and Dudeney (1973) method.

\subsection{Critical frequencies}

The behavior of the $f o \mathrm{~F} 2$ trends at Argentine Islands is similar to that found for the stations analyzed by Danilov and Mikhailov (1999a). Figure 1 shows the values of the trend $k$ (in $10^{-4}$ per year, obtained as the slope of the linear regression line for the $\delta f o \mathrm{~F} 2$ change with time, see the line in Fig.

\section{$\delta$ foF2}

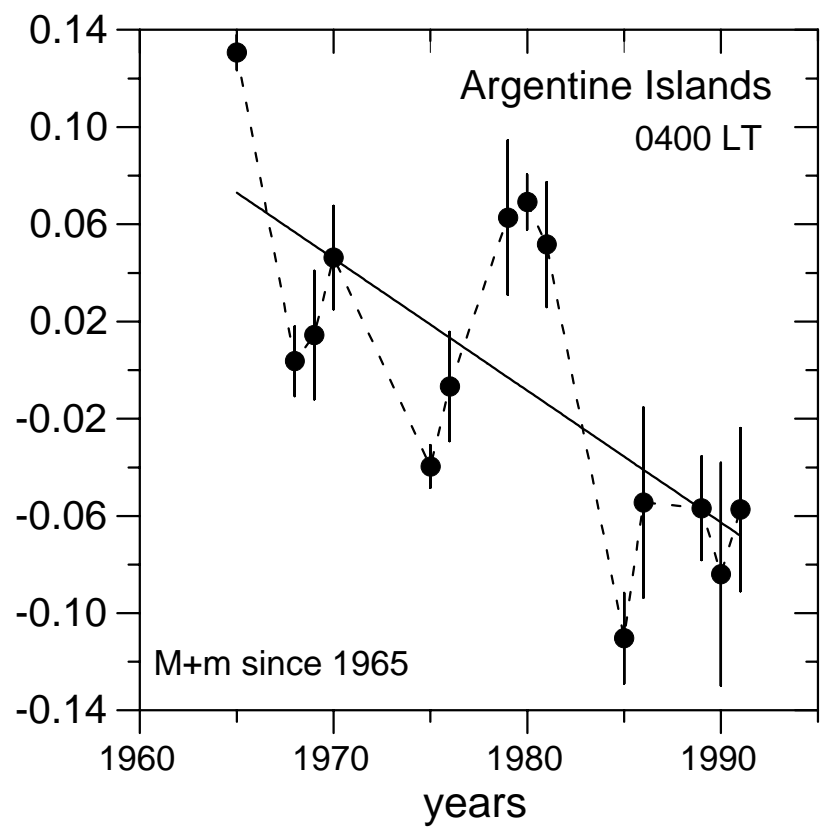

Fig. 2. Long-term $\delta f o \mathrm{~F} 2$ variations for $0400 \mathrm{LT}$ at the Argentine Islands. Solid line is a linear regression over the points. Error bars present the standard deviation of seasonal (over 12 months) scatter of $\delta f o \mathrm{~F} 2$.

2). In the same manner as in Danilov and Mikhailov (1998, 1999a), two cases are considered: all the years available and then only the years since 1965 which are around solar maxima and minima (designated below in tables and figures as $M+m$ ). Figure 2 shows an example of the $\delta f o \mathrm{~F} 2$ change with time for $0400 \mathrm{LT}$.

One can see from Fig. 1 that there is a stable negative trend even if all the years are considered. The absolute values of $k$ increase if only $M+m$ years since 1965 are considered. For the entire day, except for the 1400-2000 LT interval, the values of $k$ are significant at the $95 \%$ confidence level according to the Fisher criterion (for 0000-1000 LT, they are significant at the $99 \%$ confidence level).

The annual mean value $\mathrm{k}($ mean) for the Argentine Islands $\left(\phi=53.8^{\circ}\right)$ is $-2.4 \cdot 10^{-3}$ per year, which is close to the values for the Juliusruh $\left(\phi=54.4^{\circ}, k=-1.6 \cdot 10^{-3}\right.$ per year $)$ and Yakutsk $\left(\phi=51.0^{\circ}, k=-3.1 \cdot 10^{-3}\right.$ per year $)$ stations, with close geomagnetic latitudes in the northern hemisphere (see Danilov and Mikhailov, 1999a). Figure 1 also shows that there is a pronounced diurnal variation of $k$ with much larger values during the night and morning hours than during the noon and evening hours. Possible reasons for this variation is discussed later.

Figure 3 shows the diurnal variations of $k$ values for $\delta f o \mathrm{~F} 2$ at Port Stanley. If all the years are considered, the trend $k$ is negative for all hours and significant for the 2000-0600 LT interval. The picture is clearly different from that in Fig. 1. First, the maximum magnitude of the negative trend (at 


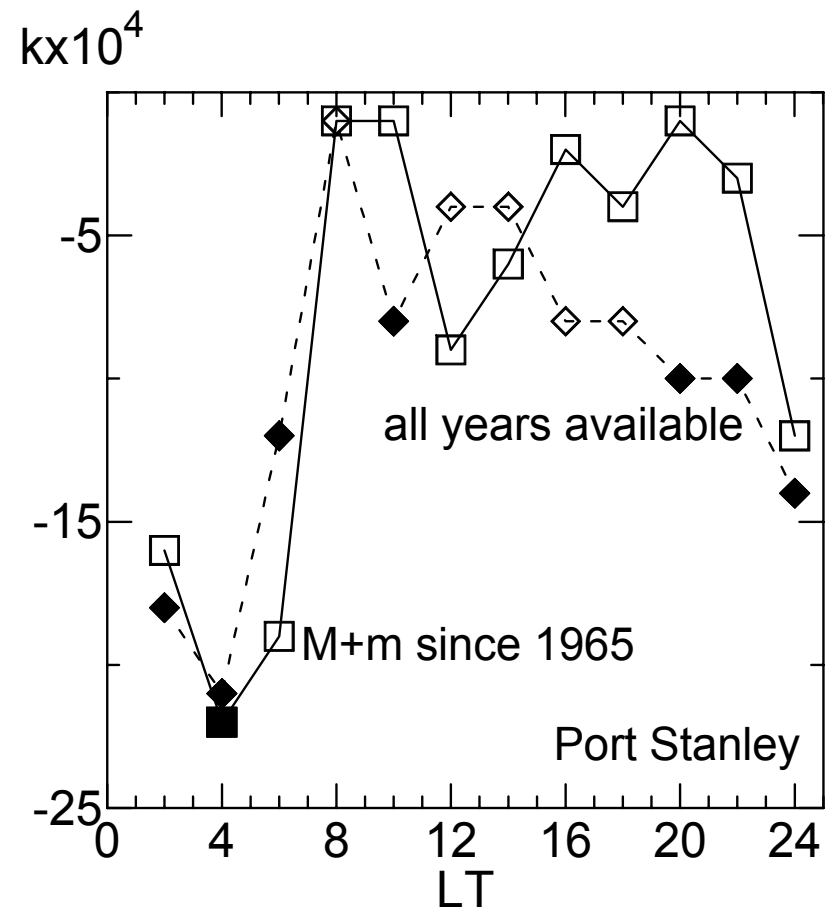

Fig. 3. The values of the $f o \mathrm{~F} 2$ trend $k$ at Port Stanley versus LT. Filled diamonds and rectangles show the data significant at the $95 \%$ level, according to the Fisher criterion, except for the 2200-0400 LT interval for all years (diamonds) where the points have a $99 \%$ significance. Open symbols correspond to statistically insignificant data at the confidence level chosen.

0400 LT) is much less than at the Argentine Islands. Second, reduction of the data to the $(M+m)$ years does not lead to any systematic effect: the values of $k(M+m)$ may be both smaller and larger than $k$ (all) and are insignificant (except at 0400 LT), according to the Fisher criterion, mainly due to the reduction of the number of points.

However, the main feature of the $k$ diurnal variation seen in Fig. 1 (higher values of the negative trends at night and early in the morning) is clearly reproduced in Fig. 3 as well. The importance of this fact will be discussed later.

The annual mean values of $k($ all $)$ and $k(M+m)$ are $-10 \cdot 10^{-4}$ and $-8 \cdot 10^{-4}$, respectively. It is only a bit lower than corresponding values of $k$ for Karaganda $\left(\phi=40.3^{\circ}\right.$, $\left.k=-1.2 \cdot 10^{-3}\right)$, Sofia $\left(\phi=41^{\circ}, k=-1.7 \cdot 10^{-3}\right.$ per year $)$, and Irkutsk $\left(\phi=41.1^{\circ}, k=-1.510^{-3}\right.$ per year $)$, which have close geomagnetic latitudes to that of Port Stanley $\left(40.6^{\circ}\right)$.

Thus, the $f o \mathrm{~F} 2$ data for both stations considered demonstrate a pronounced negative trend with the magnitude nearly the same as obtained for the corresponding $\phi$ in the analysis by Danilov and Mikhailov (1999a) for the northern hemisphere stations.

The diurnal variations of the $f o \mathrm{~F} 2$ trends for the Port Stanley station are principally the same as for the Argentine Islands and for the stations studied by Danilov and Mikhailov (1999a). However, the choice of $(M+m)$ years leads neither to an increase in the trend magnitude nor to a stable picture

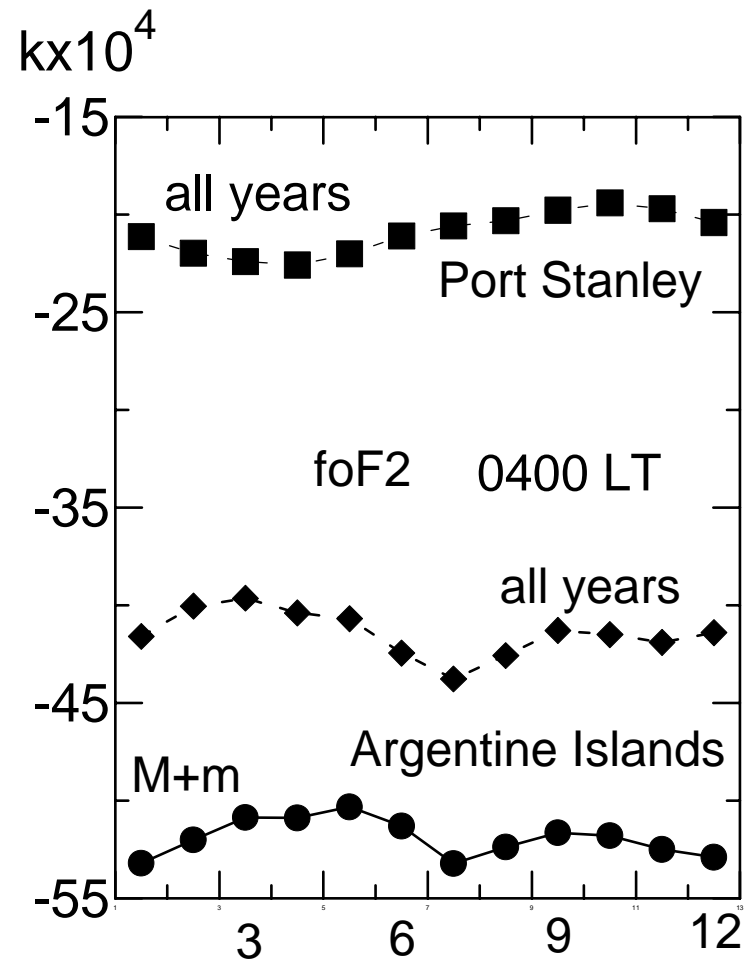

Fig. 4. Seasonal variations of the $f o \mathrm{~F} 2$ trend $k$ at two stations for $0400 \mathrm{LT}$.

of the diurnal variations.

Until now, we have considered only the annual mean values of $k$ for various LT. By considering various months, we obtain the picture of the annual variations of $k$, shown in Fig. 4 , for the particular hour 0400 LT, when, according to Figs. 1 and 3, the absolute values of $k$ have a maximum in the diurnal behavior. One can see from Fig. 4 that the seasonal variation of $k$ at both stations is relatively small if all the data are considered. The choice of $(M+m)$ years for the $\mathrm{Ar}$ gentine Islands increases the $k$ absolute values, but does not change, in principle, the seasonal behavior. At Port Stanley, the $k$ values for $(M+m)$ year selection are mainly insignificant (see Fig. 3); therefore, we do not show for them seasonal variations.

Comparing seasonal variations of $k$ for $(M+m)$ years with those at the stations considered by Danilov and Mikhailov (1999a), we see that the $k$ variations during a year (or, to be exact, the absence of pronounced seasonal variation) at the Argentine Islands agrees well with the $k$ variations at the northern hemisphere stations, with $\phi=54-64^{\circ}$ (the top panel of Fig. 3 in Danilov and Mikhailov, 1999a).

The seasonal behavior of $k$ at Port Stanley also demonstrates no pronounced seasonal variations and, in that aspect, differs from the trend behavior at the stations in the geomagnetic latitude interval $41-54^{\circ}$ (the middle panel of Fig. 3 in Danilov and Mikhailov, 1999a), which shows more pronounced seasonal effect in $k$. It is possible that the processes of the F2 layer formation at Port Stanley may be different 


\section{$\delta \mathrm{hmF2}$}

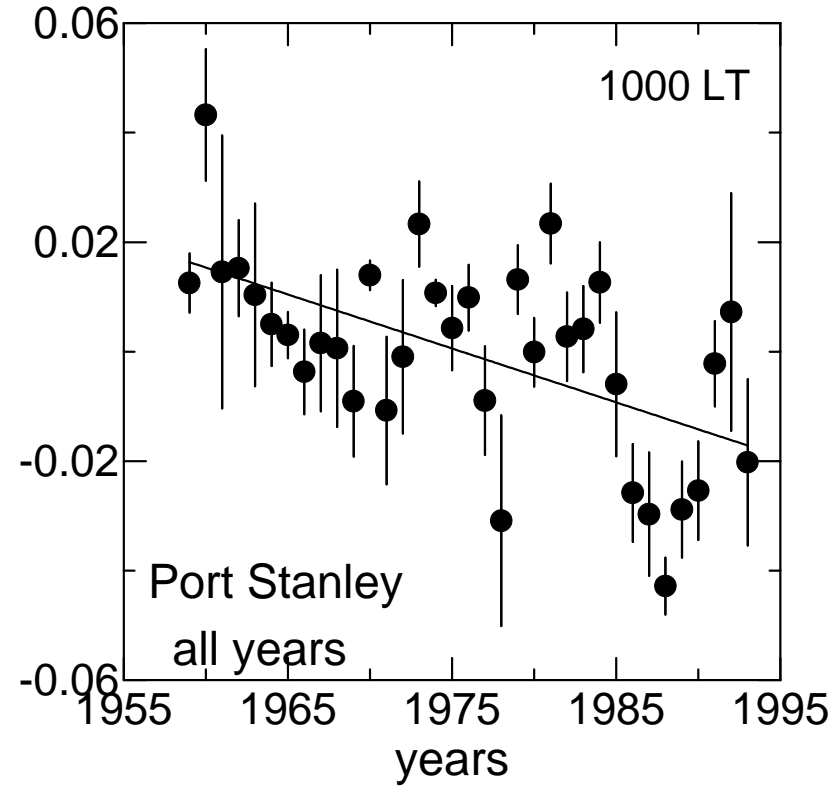

Fig. 5. Variations of annual mean $\delta h m \mathrm{~F} 2$ with time at Port Stanley. The designations are the same as in Fig. 2.

from the usual ones. This may be due, in particular, to the fact that the station is close to the South-Atlantic Geomagnetic Anomaly and, therefore, processes of direct corpuscular ionization may play some role in the F2 layer formation and thus, disturb the "normal" picture of $f o \mathrm{~F} 2$ and $h m \mathrm{~F} 2$ behavior.

Since the amplitude of the seasonal variation at both stations is relatively small (much smaller than the amplitude of diurnal variations), we will not come back to this point and consider only annual mean values of $k$ in the further analysis.

\subsection{F2-layer maximum heights}

Similar analysis was performed for the $h m \mathrm{~F} 2$ data at the same two stations. An example of $\delta h m \mathrm{~F} 2$ variation with time at Port Stanley is shown in Fig. 5. The values of the trends at both stations obtained for two cases (all the years and only the $(M+m)$ years since 1965) are shown in Table 1. Bold numerals show the $k$ values at the $95 \%$ significance level, according to the Fisher criterion; the significance of all other values of $k$ are below the latter value.

Table 1 shows that for the Argentine Islands, we obtain no pronounced regular diurnal variation. All the $k$ values have a significance below the $95 \%$ level. On the basis of these values, we can only state that the $h m \mathrm{~F} 2$ trend tends to be positive.

The behavior of $k$ for $h m \mathrm{~F} 2$ for Port Stanley is quite different (see Table 1). First, all the $k$ values obtained for all the years are negative; on the average, there is a stable negative trend of about $10^{-3}$ per year. There is some tendency for diurnal variations with lower absolute values of $k$ around noon, and higher values around midnight. Table 1 demonstrates that all the values of $k$ for the $(M+m)$ years are insignif-

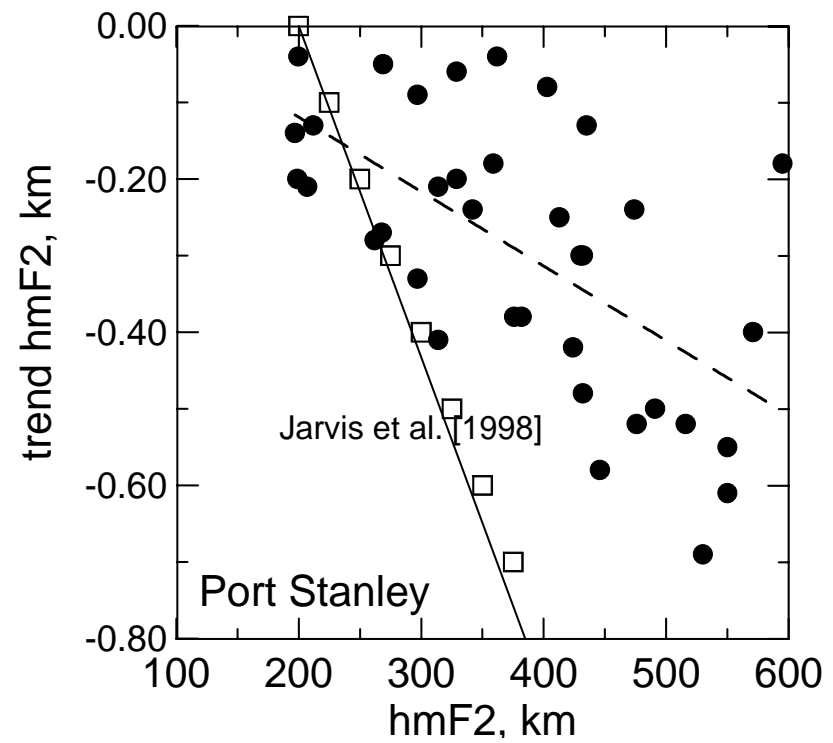

Fig. 6. Absolute values of $h m \mathrm{~F} 2$ trends versus $h m \mathrm{~F} 2$. Dashed line is a linear regression over the individual $\Delta h m \mathrm{~F} 2$ values (points). Solid line represents similar regression over the individual points taken from Fig. 6 in Jarvis et al. (1998). Open rectangles correspond to the case of constant $k=-4 \cdot 10^{-3}$ per year.

icant at the level considered. Evidently, for some unknown reason, the choice of the $(M+m)$ years does not work in the case of the $h m \mathrm{~F} 2$ data, as it works for $f o \mathrm{~F} 2$, over the set of the northern hemisphere stations (Danilov and Mikhailov, 1999a) and for the Argentine Islands (see the previous section). Therefore, in the following analysis of the $h m \mathrm{~F} 2$ data, we are considering only the "all years" case.

In continuation, we may note that the method used gives negative trends of $f_{o} \mathrm{~F} 2$ for both stations considered. Annual mean $k$ values agree reasonably well with the $f \circ \mathrm{F} 2$ trends for the northern hemisphere stations with close geomagnetic latitudes. The $(M+m)$ year selection after 1965 increases the values of $k$ at the Argentine Islands, but does not, in principle, change the picture of the $k$ diurnal behavior. At Port Stanley, most of the $k$ for the $(M+m)$ years are of low significance.

The picture for the $h m \mathrm{~F} 2$ trends is different. The Argentine Island data demonstrate an absence of pronounced trends, whereas at Port Stanley, there is a stable negative trend of about $10^{-3}$ per year.

\section{Comparison with the Jarvis at al. (1998) results}

The method used here gives the trends in relative units per year. To compare our results with the results of absolute trend determinations, one needs absolute values of the parameters analyzed. One of the important results of the Jarvis et al. (1998) analysis was the determination of the direct relation between the absolute trend $\Delta h m$ and the value of $h m \mathrm{~F} 2$ itself. Jarvis et al. (1998) used values for each hour of every month, 
Table 1. The $h m \mathrm{~F} 2$ trend $k$ in $10^{-4}$ per year

\begin{tabular}{lcccccccccccc}
\hline LT & 00 & 02 & 04 & 06 & 08 & 10 & 12 & 14 & 16 & 18 & 20 & 22 \\
\hline \multicolumn{1}{c}{ Argentine Islands } \\
\hline all & -01 & +01 & +01 & -02 & -06 & +01 & +08 & +09 & +05 & +09 & +01 & -03 \\
$(M+m)$ & +09 & +13 & +09 & +04 & -03 & +01 & +13 & +12 & +11 & +10 & +02 & +02 \\
\hline \multicolumn{10}{c}{ Port Stanley } \\
\hline all & -13 & -07 & -03 & -10 & -10 & -10 & -05 & -07 & -06 & -02 & -11 & -11 \\
$(M+m)$ & -02 & +01 & -02 & -03 & -07 & -09 & -02 & -08 & -05 & -03 & -05 & -04 \\
\hline
\end{tabular}

so they had a huge set of points in their Fig. 6.

To simulate their result, we used the values of the relative trends $k$ shown in Table 1 for Port Stanley. To transfer from a relative trend to an absolute one, one has to multiply the former by a corresponding value of $h m \mathrm{~F} 2$. We arbitrarily took the monthly mean $h m \mathrm{~F} 2$ values for Port Stanley for 24 LT moments for January 1958 (solar maximum), June 1975 (solar minimum), and January 1989 (solar maximum). The use of the years of solar maxima and minima made it possible to cover a wider range of the $h m \mathrm{~F} 2$ variations. Multiplying $h m \mathrm{~F} 2$ by the corresponding $k$ provided the absolute trend $\Delta h m$ in $\mathrm{km}$. It is evident that we are able to add to this figure as many points as we wish, using various months and years, but we limited ourselves by the three months indicated above, and obtained the points shown in Fig. 6, which are aimed at merely an illustration of the idea.

Thus, points in Fig. 6 show individual values of $\Delta h m \mathrm{~F} 2$ obtained in the previously mentioned method and the dashed line is a least square linear regression. This part of Fig. 6 is qualitatively completely similar to Fig. 6 in Jarvis et al. (1998). To make a quantitative comparison, we present in our Fig. 6 a solid line which is taken from Fig. 6 in Jarvis et al. (1998) and shows a similar regression of $\Delta h m \mathrm{~F} 2$ versus $h m \mathrm{~F} 2$. To avoid complicating the figure, we cannot present all the original points shown in the Jarvis et al. (1998) Fig. 6 and thus show, only the regression line.

One can see from Fig. 6 that our results reproduce a principal dependence of the absolute $h m \mathrm{~F} 2$ trend on $h m \mathrm{~F} 2$ itself, as obtained by Jarvis et al. (1998), but the slope of our regression line (the dashed line) is lower than that of Jarvis et al. (1998). Our slope corresponds to a mean relative trend $k$ of about $-8 \cdot 10^{-4}$ per year (in fact, it was the value taken to calculate the absolute values of $\Delta h m \mathrm{~F} 2$, as was described above). One can see from Fig. 6 that the slope of the regression line (solid line) obtained by Jarvis et al. (1998) is steeper. The rectangles in our Fig. 6 correspond to the relative trend of $-410^{-3}$ per year. One can see that the rectangles fit well the regression line taken from Jarvis et al. (1998).

Thus, there is a difference in the slopes $k$ (relative trends) between the $\Delta h m \mathrm{~F} 2$ on $h m \mathrm{~F} 2$ dependencies obtained by Jarvis et al. (1998) and in the present paper. The difference may be due to the different methods of trend determination in both approaches and to the different amount of points used.
But this is not important for the present consideration. The important thing is that actually the dependence of $\Delta h m \mathrm{~F} 2$ on $h m \mathrm{~F} 2$ found by Jarvis et al. (1998) is just a consequence of the fact that the relative trend of $h m \mathrm{~F} 2$ is constant and this leads to an decrease of $\Delta h m$ with a decrease of $h m$ itself. If the relative trend were absolutely constant (in fact, it is not so as the $h m \mathrm{~F} 2$ trend does depend on LT, season, magnetic activity and possibly other factors), Jarvis et al. (1998) would have a direct line in their Fig. 6 (right panel) with the slope equal to $-4 \cdot 10^{-3}$ per year and no scatter of the points. However, the seasonal, diurnal and other variations of the relative trend (which do exist in reality) determine the scatter of the points relative to this line, which is actually seen in Fig. 6 (right panel) in Jarvis et al. (1998).

In case of the Argentine Islands data, it is difficult to simulate the Jarvis et al. (1998) results with the data presented in Table 1. One can see that the relative trend $k$ for the Argentine Islands changes sign and is of low significance. The lefthand panel of Fig. 6 in Jarvis et al. (1998) shows that about one-third of all $\Delta h m \mathrm{~F} 2$ points lie above the zero line, indicating positive trends, with the rest showing negative $\Delta h m \mathrm{~F} 2$ values. The approximating line in their figure corresponds to about $k=-2 \cdot 10^{-3}$ per year. Strong scatter of the individual points in both parts of that figure shows that actually the relative trend $k$ is rather changeable, depending evidently on both LT and season.

We will return back to the problem of the $h m \mathrm{~F} 2$ trends below, considering the $\delta f o \mathrm{~F} 2$ and $\delta h m \mathrm{~F} 2$ relation to the $A p$ index.

\section{Analysis of the $\delta f o F 2$ and $\delta h m \mathrm{~F} 2$ variations}

In all the analyses described in the previous section, the values of $\delta f o \mathrm{~F} 2$ and $\delta h m \mathrm{~F} 2$ determined from the experimental data according to Eqs. (1) and (2), respectively, were used to analyze the general tendency of their variation with time to find the slope $k$ of the approximating line. One can see from Figs. 2 and 5 that even when the tendency is well pronounced and there is no doubt of the $\delta f_{o} \mathrm{~F} 2$ (or $\delta h m \mathrm{~F} 2$ ) behavior with time, there are considerable deviations of the $\delta f o \mathrm{~F} 2$ and $\delta h m \mathrm{~F} 2$ from the regression line. Let us consider the question in more detail. One should remember that the $\delta f o \mathrm{~F} 2(\delta h m \mathrm{~F} 2)$ values are deviations of the real data from 


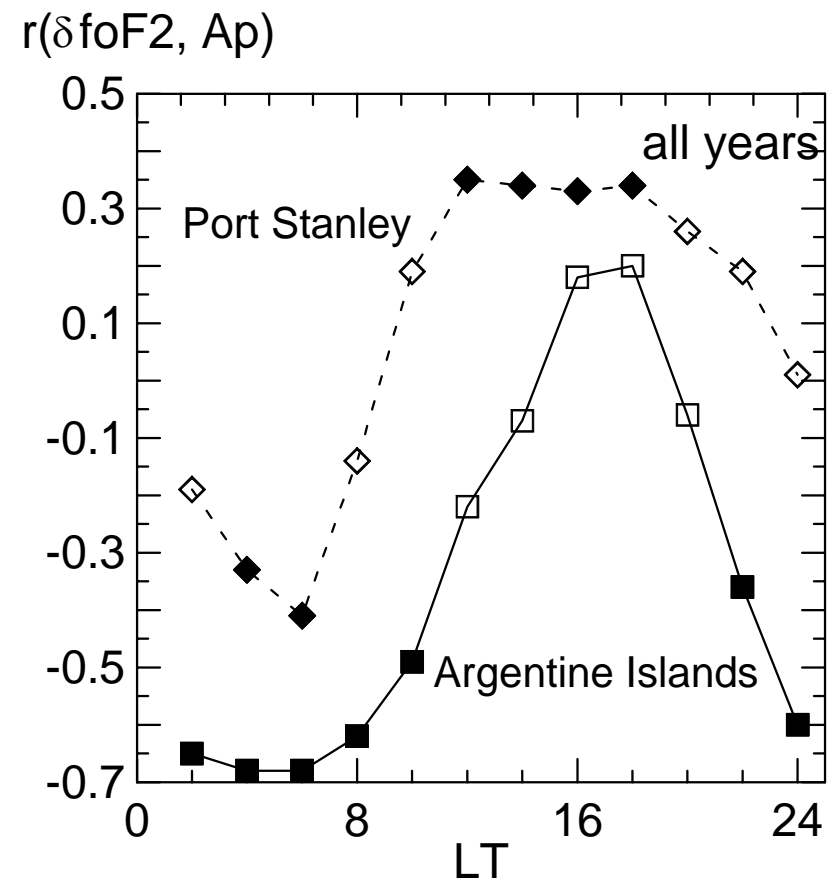

Fig. 7. Diurnal variations of the correlation coefficient $r(\delta f o \mathrm{~F} 2$, $\left.A p_{12}\right)$ for the two stations. Filled symbols for the Argentine Island mean a significance at the $99 \%$ level, according to the Fisher criterion (except the $2200 \mathrm{LT}$ point which is of the $90 \%$ significance). Filled symbols for Port Stanley mean a significance at the $95 \%$ level (except the 0400 LT point which is of the $90 \%$ significance). Open symbols for both stations mean a significance below $90 \%$.

some model: the $f o \mathrm{~F} 2$ (or $h m \mathrm{~F} 2$ ) regression with solar index $R_{12}$. Actually, there might be other factors changing from year to year and leading to deviations of the observed $\delta f o \mathrm{~F} 2$ $(\delta h m \mathrm{~F} 2)$ values from the model, which takes into account only the changes described by $R_{12}$. The most probable are two such factors: long-term changes of geomagnetic activity, resulting in long-term trends of the aeronomical parameters (neutral composition, temperature, winds), and changes in solar EUV not properly presented by $R_{12}$ variations.

The search for the long-term variations of the F2-layer parameters, in fact, was stimulated by theoretically predicted in the beginning of the 1990s, the changes in $f o \mathrm{~F} 2$ and $h m \mathrm{~F} 2$ due to the increase in the greenhouse gases in the vicinity of the mesopause and the corresponding cooling of this region (Rishbeth, 1992; Rishbeth and Roble, 1992). Therefore, the results of all attempts to detect the trends in $f o \mathrm{~F} 2$ and/or $h m \mathrm{~F} 2$ (see detailed references in Danilov and Mikhailov (1999a) and the reviews by Danilov $(1997,1998))$ were interpreted in terms of changes of the F-region aeronomical parameters. Danilov and Mikhailov (1999 a.b) were the first to show that the magnitude of the negative trend in $f o \mathrm{~F} 2$ strongly depends on the geomagnetic (not geographic) latitude, with the magnitude being higher at high geomagnetic latitudes. This fact put considerable doubts on the "greenhouse" nature of the trends detected, and led Danilov and Mikhailov (1999a) to assume that these trends may be re- lated to the trends in the occurrence of ionospheric storms, as reported by a group of authors (Sergeenko and Kuleshova, 1994, 1995; Sergeenko and Givishvily, 1997). Mikhailov and Marin (2000) analyzed the relation of the foF2 behavior to geomagnetic activity and demonstrated that the annual mean values of $\delta f o \mathrm{~F} 2$ at three stations (Slough, Moscow, and Tomsk) correlate to the annual mean values of the $A p$ geomagnetic index. This does not mean that there cannot exist other $f o \mathrm{~F} 2$ and $h m \mathrm{~F} 2$ trends of the "greenhouse" or other nature, but the input of the geomagnetic trend into foF 2 and $h m \mathrm{~F} 2$ long-term changes seems evident.

Coming back now to the analysis of the Argentine Islands and Port Stanley data, we will analyze individual values of $\delta f o \mathrm{~F} 2$ and $\delta h m \mathrm{~F} 2$ to determine whether they present merely random deviations from the smooth behavior described by the model, or one or both factors mentioned above play a part in determining their behavior.

\subsection{Comparison with geomagnetic activity}

To analyze the relation of the $\delta f o \mathrm{~F} 2$ and $\delta h m \mathrm{~F} 2$ values with geomagnetic activity, we used the annual mean values of the $A p_{12}$ geomagnetic index. These values were compared with $\delta f o \mathrm{~F} 2$ and $\delta h m \mathrm{~F} 2$ for each particular situation considered and the corresponding correlation coefficients were calculated. Since the diurnal variations of both parameters are better pronounced than the seasonal ones (see the previous section), we used the annual mean $\delta f o \mathrm{~F} 2$ and $\delta h m \mathrm{~F} 2$ values and considered only the diurnal variations. We have found that the choice of $(M+m)$ years since 1965 in the $\delta h m \mathrm{~F} 2$ case does not lead to any significant difference in the correlation coefficient obtained; thus, we considered all the data, because in this case, the statistical provision of the results is much better.

Figure 7 shows the correlation coefficient $r\left(\delta f o \mathrm{~F} 2, A p_{12}\right)$ for both stations as a function of the local time. Several features of Fig. 7 should be noted: 1) there is an evident similarity in the diurnal behavior of $r\left(\delta f o \mathrm{~F} 2, A p_{12}\right)$ at both stations. It may be considered as a first proof that the $\delta f o \mathrm{~F} 2$ values are not merely occasional deviations from the model but, at least partly, are a manifestation of the magnetic activity not taken into account in the model; 2) there is an important feature in both curves: the values of $r\left(\delta f o \mathrm{~F} 2, A p_{12}\right)$ are positive in the afternoon and negative at midnight and in the early morning periods; 3 ) at the Argentine Islands, the maximum positive value of $r\left(\delta f o \mathrm{~F} 2, A p_{12}\right)$ is relatively small (around 0.1) and insignificant. In fact, Fig. 7 shows that in the afternoon and early evening periods, there is practically no significant correlation between $\delta f o \mathrm{~F} 2$ and $A p_{12}$. Contrary to that, the negative correlation between $\delta f o \mathrm{~F} 2$ and $A p_{12}$ during the night is well pronounced (the value of $r$ being about 0.6-0.7 during several hours) and statistically significant; 4) at Port Stanley, the values of the $r\left(\delta f_{o} \mathrm{~F} 2, A p_{12}\right)$ are about 0.3 and -0.4 in the afternoon maximum and early morning minimum, respectively. The difference in the two curves in Fig. 7 encourages us to assume that the mechanisms of the magnetic influence on $f o \mathrm{~F} 2$ at the two stations are different, 
which may be due to the fact that Port Stanley is close to the region of the South-Atlantic Geomagnetic Anomaly and additional sources of ionization may govern the F2-region behavior there.

\subsection{Possible relation to ionospheric storms}

Now we try to consider all the experimental evidence described above in terms of the hypothesis that long-term changes in geomagnetic activity (and corresponding number and intensity of ionospheric storms) is the most probable cause of the described behavior of $\delta f o \mathrm{~F} 2$ and $\delta h m \mathrm{~F} 2$.

According to the contemporary understanding of the ionospheric storm physics and morphology (see the reviews by Prölls, 1995; Field and Rishbeth, 1998; Rees, 1995; Danilov, 2000), the principal scheme of an ionospheric storm looks like the following: the Joule heating in the auroral zone changes the thermospheric composition (increases the molecule-to-atom ratio), increases the neutral gas temperature and generates storm-induced global circulation. Changes in the aeronomical parameters $\left(\left[\mathrm{N}_{2}\right] /[\mathrm{O}]\right.$ and $\left.T\right)$ lead to a decrease of the electron concentration (or $f_{o} \mathrm{~F} 2$ ) in the heated gas. This is the negative phase of an ionospheric storm. The storm-induced circulation tends to bring the heated gas from the auroral zone equatorward to lower latitudes. How far this gas really penetrates down the latitudes depends on the competition between the storm-induced and normal (solar driven) circulation. The latter depends on season and local time. During the daytime, in winter, the solar driven circulation is directed poleward and thus, opposite to the storm-induced circulation. In this case, the heated gas may stay "locked" in the zone of the Joule heating or drift only slightly to lower latitudes. In the night the situation is different. The solar driven background circulation is weakened and can no longer completely stop the storm-induced circulation; the gas with changed temperature and composition moves down the latitudes and the negative phase may be observed at relatively low latitudes (down to $\phi=35-40^{\circ}$ ). In summer the storm-induced and solar-driven background circulation coincide practically all day long and thus, the heated gas reaches low enough latitudes. Two points of the described simplified scheme are important for our analysis. First, at moderate latitudes, the negative phase, on the whole, is observed more often than the positive one. Second, the most favorable conditions for the negative phase occurrence are at night and early in the morning, when in all seasons, the storm-induced circulation is able to penetrate to moderate latitudes and bring the heated gas with changed temperature and composition.

Let us consider how, in this paper as well as in Danilov and Mikhailov (1999a, b), Mikhailov and Marin (2000), the revealed features of the $\delta f o \mathrm{~F} 2$ and $\delta h m \mathrm{~F} 2$ behavior can be interpreted in terms of long-term variations in geomagnetic activity and related changes in number and intensity of ionospheric storms.

As it was mentioned earlier, the negative phase of an ionospheric storm is observed mostly at night. Therefore, one

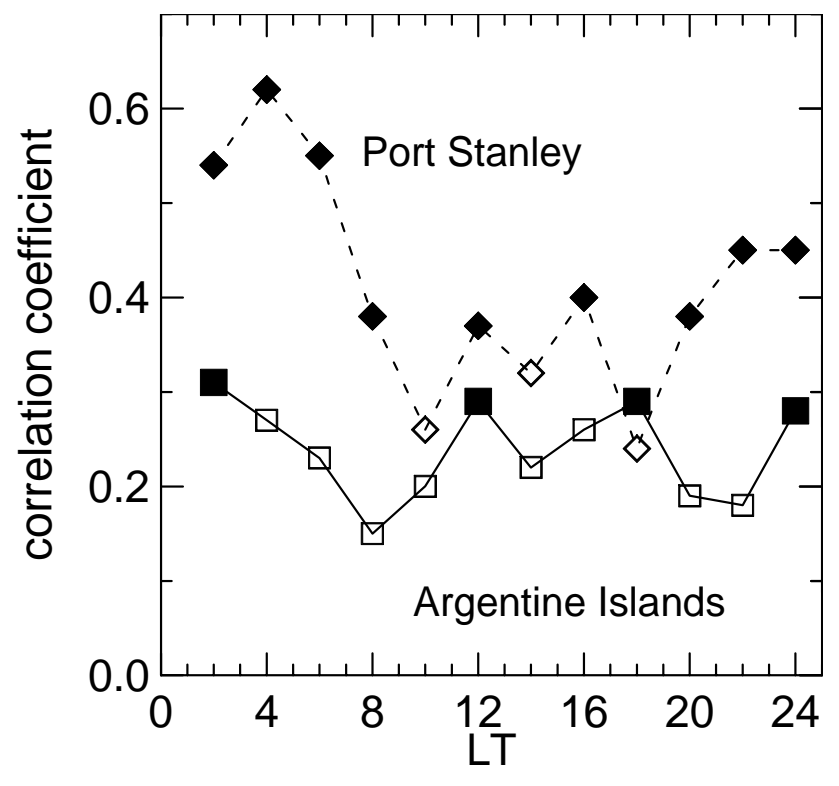

Fig. 8. Diurnal variations of the correlation coefficient $r(\delta h m \mathrm{~F} 2$, $A p_{12}$ ) for the two stations. Filled symbols for the Argentine Island mean a significance at the $90 \%$ level, according to the Fisher criterion. Filled symbols for Port Stanley mean a significance at the 95\% level (except the 2200-0600 LT interval where the points are of the $99 \%$ significance). Open symbols for both stations mean a significance below $90 \%$.

would expect negative $f o \mathrm{~F} 2$ trends to be better pronounced at night and early in the morning. This is exactly what we see in Fig. 1 for the Argentine Islands. This station lies at the latitude where, according to the analysis of the latitude dependence of the $f o \mathrm{~F} 2$ trends by Danilov and Mikhailov (1999a) and Mikhailov and Marin (2000), the negative phase effects should be well manifested. The diurnal behavior of $k$ for $\delta f o \mathrm{~F} 2$ at the Argentine Islands agrees well with that for Moscow, as obtained by Mikhailov and Marin (2000) for the period after 1965. The maximum negative trends of about -0.003 per year were found there at 0000-0600 LT and the minimum trends of about -0.001 per year are seen in the afternoon hours.

Thus, diurnal variations of the $f o \mathrm{~F} 2$ trends at the Argentine Islands agree with the assumption that the negative trends may be due to an occurrence frequency increase of the ionospheric storm negative phase. The analysis of the $\delta f o \mathrm{~F} 2$ correlation with $A p_{12}$ (Fig. 7) also works in the same direction. The strongest (negative!) correlation is seen in the midnightearly morning period, whereas in the daytime, the correlation coefficient changes sign and is small in magnitude.

The diurnal variation of $k$ at Port Stanley (Fig. 3) is not as regular as that at the Argentine Islands. Nevertheless, the principal for our consideration feature, a strong nighttime maximum, does exist, thus, confirming the previous conclusion. The correlation coefficient of $\delta f o \mathrm{~F} 2$ with $A p_{12}$ (see Fig. 7) shows the same type of diurnal variation as at the Argentine Islands, but with different values. Negative values of $r\left(\delta f o \mathrm{~F} 2, A p_{12}\right)$ at night are less $(-0.3)$ and there is a long 
period of relatively low but stable positive correlation in the daytime.

We think that the features described above in the diurnal variations of $k$ and $r\left(\delta f o \mathrm{~F} 2, A p_{12}\right)$ at Port Stanley are a manifestation of a peculiar ionization cycle governing the electron concentration behavior at this station. Probably an increase of the magnetic activity enhances corpuscular ionization of the F2-region. If this is true, two factors affect the behavior of $f o \mathrm{~F} 2$ when $A p_{12}$ is increasing: the effect of ionospheric storm negative phase should be reduced (that is exactly what we see at night) and there should be even positive correlation with $A p_{12}$ in the daytime, when the probability of the negative phase occurrence is relatively low.

Also understandable in the scope of the simplified scheme of the ionospheric storm development described seems to be the behavior of two correlation coefficients during the night. We have already mentioned that this period is the most favorable for penetration of the storm-induced circulation down the latitudes. The equatorward wind, along with an increase of $\beta$ (due to $\gamma_{1,2}$, [ $\left.\mathrm{N}_{2}\right]$, and $\left[\mathrm{O}_{2}\right]$ ), results in the $h m \mathrm{~F} 2$ increase. Here, $\beta$ is the linear recombination coefficient, and $\gamma_{1}$ and $\gamma_{2}$ are the rate constants of the reactions of $\mathrm{O}^{+}$with $\mathrm{N}_{2}$ and $\mathrm{O}_{2}$ molecules, respectively. At the same time, the increase of $\beta$ should lead to a decrease in $f o \mathrm{~F} 2$, which is manifested by a strong negative correlation between $\delta f o \mathrm{~F} 2$ and $A p_{12}$ in Fig. 7 for this period.

Figure 7 shows that diurnal variations of the correlation coefficient $r\left(\delta f_{o} \mathrm{~F} 2, A p_{12}\right)$ are similar for both stations. The only difference is that at the Argentine Islands, the daytime maximum of $r\left(\delta f o \mathrm{~F} 2, A p_{12}\right)$ is narrow and has smaller amplitude than at Port Stanley. This may be due to the fact that the geomagnetic latitude of the Argentine Islands is significantly higher than that of Port Stanley; thus, the effect of the heated gas from high latitudes should be stronger at the former station, leading to a larger input of the negative phase and thus, leading to a general shift of the $r\left(\delta f o \mathrm{~F} 2, A p_{12}\right)$ curve in Fig. 7 in the direction of negative correlation.

Variations of $h m \mathrm{~F} 2$ during ionospheric storms are controlled by increased neutral temperature $T_{n}$, linear loss coefficient $\beta=\gamma_{1}\left[\mathrm{~N}_{2}\right]+\gamma_{2}\left[\mathrm{O}_{2}\right]$, and vertical plasma drift related to thermospheric winds and electric fields. Magnetospheric electric fields produce short-term $h m \mathrm{~F} 2$ variations and may not be considered in the long-term trend analysis. The first three parameters are known to increase during disturbed periods, resulting in the $h m \mathrm{~F} 2$ increase at middle and lower latitudes (Mikhailov et al., 1995).

For this consideration, it is important that during ionospheric storms, $h m \mathrm{~F} 2$, in almost all cases, should increase. Therefore, one would expect only a positive correlation between $\delta h m \mathrm{~F} 2$ and magnetic activity. This was also shown by Marin et al. (2001) for many northern hemisphere stations. Actually, positive values of $r\left(\delta h m \mathrm{~F} 2, A p_{12}\right)$ are seen at both stations in Fig. 8. The correlation coefficient of $\delta h m \mathrm{~F} 2$ with $A p_{12}$ at Port Stanley is significant for most of the LT moments and higher at night (0.5-0.6) than in the daytime. The values of $r\left(\delta h m \mathrm{~F} 2, A p_{12}\right)$ at the Argentine Islands are much lower and insignificant.
In spite of the positive correlation between $\delta h m \mathrm{~F} 2$ and $A p_{12}$, negative long-term trends of $h m \mathrm{~F} 2$ at Port Stanley are obtained both in Jarvis et al. (1998) and this paper. Since there is a well-known long-term increase of magnetic activity (see e.g. Clilverd et al., 1998), one would expect a positive trend of $h m \mathrm{~F} 2$. However, the Port Stanley is a peculiar station. Since it is in the vicinity of the South-Atlantic Magnetic Anomaly, the magnetic storms at this station may be manifested not only by the aeronomical parameter changes discussed above, but also by corpuscular precipitation. Such precipitation would increase the ionization rate $\mathrm{q}$ and change the electron concentration vertical profile in the entire $\mathrm{F}$ region, shifting it down in such a way that the maximum of the electron concentration would tend to be lower than in quiet conditions. It is evident that this effect, if it exists, should be pronounced at high-latitude stations, where magnetic disturbances are accompanied by particle precipitation. In fact, the same effect of negative trends have been found by Marin et al. (2001) for several high-latitude stations and above all, for Sodankyla.

\section{Conclusions}

In this paper we applied the method developed and described earlier to look for long-term trends of the F2-layer parameters $(f o \mathrm{~F} 2$ and $h m \mathrm{~F} 2)$ at two southern hemisphere ionospheric stations, the Argentine Island and Port Stanley, recently considered by Jarvis et al. (1998). The main results of our analysis may be listed as follows:

1. Negative $f o \mathrm{~F} 2$ trends are observed at both stations. The average value of the trend $k$ for the Argentine Island is -2.4 . $10^{-3}$ per year, which is close to the values of $k$ obtained for the stations with similar geomagnetic latitude in the northern hemisphere. For Port Stanley, the averaged value $k=$ $-8 \cdot 10^{-4}$ per year is also only slightly lower than the $k$ values for the corresponding stations considered by Danilov and Mikhailov (1999b). It is worth noting that the principal conclusions based on the analysis of the northern hemisphere stations are confirmated: the $f o \mathrm{~F} 2$ trends are negative and demonstrate a pronounced diurnal behavior.

2. The diurnal variation of $k$ for $f o \mathrm{~F} 2$ at the Argentine Island is well pronounced and similar to the diurnal variations at the corresponding northern hemisphere stations, with maximum amplitudes of the negative trend at night and in the early morning hours, and a minimum in the afternoon. The diurnal variation of $k$ at Port Stanley is less systematic (especially during daytime), but shows a pronounced maximum at night. The irregularity of the diurnal behavior of $k$ at Port Stanley may be due to its peculiar position close to the South Atlantic Geomagnetic Anomaly.

3. The increase of the magnitude of the absolute trend $\Delta h m \mathrm{~F} 2$ with an increase in $h m \mathrm{~F} 2$ itself, found by Jarvis et al. (1998) for Port Stanley, is merely a manifestation of a relative constancy of the relative trend which, in this case, is equal to $-4 \cdot 10^{-3}$ per year.

4. The analysis of the local time variations of the cor- 
relation coefficients between $\delta f o \mathrm{~F} 2, \delta h m \mathrm{~F} 2$ and $A p_{12}$ shows that they principally agree with the current understanding of ionospheric storm physics and morphology. This means that the long-term trend in ionospheric storms found by various authors can contribute significantly to the long-term trends in $f o \mathrm{~F} 2$ and $h m \mathrm{~F} 2$ and mask significantly the effects (if any) of a greenhouse gas increase.

Acknowledgements. The authors thank Dr. M. Jarvis for providing the $h m \mathrm{~F} 2$ data and discussion of the paper.

Topical Editor M. Lester thanks C. Davis and J. Lastovicka for their help in evaluating this paper.

\section{References}

Bencze, P., Sole, G., Alberca, L. F., Poor, A., Long-term changes of $h m \mathrm{~F} 2$ possible latitudinal and regional variations, Proc. 2nd COST 251 Workshop "Algorithms and Models for COST 251 Final Product”, Rutherford Appleton Lab., UK, 107-113, 1998.

Bradley, P. A. and Dudeney, J. R., A simple model of the vertical distribution of electron concentration in the ionosphere, J. Atmos. Terr. Phys. 35, 2131-2146, 1973.

Bremer, J., Some additional results of long-term trends in verticalincidence ionosonde data, Paper presented at the COST 251 Meeting, Prague, September 1996.

Bremer J., Trends in the ionospheric E and F regions over Europe, Ann. Geophysicae, 16, 986-996, 1998.

Danilov, A. D., Long-term changes of the mesosphere and lower thermosphere temperature and composition, Adv. Space Res., 20, 2137-2147, 1997.

Danilov, A. D., Review of long-term trends in the upper mesosphere, thermosphere, and ionosphere, Adv. Space Res., 22, $907-$ 915, 1998.

Danilov, A. D., F-region reaction to magnetospheric storm, J. Atmos. Terr. Phys., in press, 2000.

Danilov, A. D. and Mikhailov, A. V., Long-term trends of the F2layer critical frequencies: a new approach, Proc. 2nd COST 251 Workshop "Algorithms and Models for COST 251 Final Product", Rutherford Appleton Lab., UK, 114-121, 1998.

Danilov, A. D. and Mikhailov, A. V., Spatial and seasonal variations of the $f o \mathrm{~F} 2$ long-term trends, Ann. Geophysicae, 17, 1239-1243, 1999a.

Danilov, A. D. and Mikhailov, A. V., Long-term trends of the F2layer parameters: a new approach, Int. Journ. Geomag. Aeron. (http://eos.wdcb.rssi.ru/ijga), 1, (3), 1999b.

Field, P. R., Rishbeth, H., Moffett, R. J. et al., Modeling composition changes in F-layer storms, J. Atmos. Solar Terr. Phys., 60, 523-543, 1998.

Givishvili, G. V. and Leshchenko, L. N., Long-term trends of the properties of the midlatitude ionosphere and thermosphere, Dokl. RAN (in Russian), 333 (1), 86-92, 1993.

Givishvili, G. V. and Leshchenko, L. N., Possible proof of the presence of technogenic impact on the midlatitude ionosphere, Dokl.
RAN (in Russian), 334 (2), 213-214, 1993.

Jarvis, M. J., Jenkins, B., and Rogers, G. A., Southern hemisphere observations of a long-term decrease in $\mathrm{F}$ region altitude and thermospheric wind providing possible evidence for global thermospheric cooling, J. Geophys. Res., 103, 20744-20787, 1998.

Klilverd, M. A., Clark, T. D. G., Clarke, E., and Rishbeth, H., Increased magnetic storm activity from 1968 to 1995, J. Atmos. Terr. Phys., 60, 1047-1056, 1998.

Marin, D., Mikhailov, A. V., de la Morena, B. A., and Herraiz, M., Long-term $h m \mathrm{~F} 2$ trends in the Eurasian longitudinal sector on the ground-based ionosonde observations, Ann. Geophysicae, submitted, 2001.

Mikailov, A. V., Skoblin, M. G., and Förster, M., Daytime F2-layer positive storm effect at middle and lower latitudes, Ann. Geophysicae, 13, 532-540, 1995.

Mikhailov, A. V. and Marin, D., Geomagnetic control of the $f_{o} \mathrm{~F} 2$ trends, Ann. Geophysicae, 18, 653-665, 2000.

Mikhailov, A. V. and Marin, D., An interpretation of the $f o \mathrm{~F} 2$ and $h m \mathrm{~F} 2$ long-term trends in the framework of the geomagnetic control concept, Ann. Geophysicae, submitted, 2001.

Prölls, G., Ionospheric F-region storms, in Handbook of Atmospheric Electrodynamics, Vol 2, Ed. H. Volland, CRC Press/Boca Raton, 195-248, 1995.

Rees, D., Observations and modeling of ionospheric and thermospheric disturbances during major geomagnetic storms: A review, J. Atmos. Terr. Phys., 57, 1433, 1995.

Rishbeth, H., A greenhouse effect in the ionosphere? Planet. Space Sci., 38, 945-948, 1990 .

Rishbeth, H., How the thermospheric circulation affects the ionospheric F2-layer, J. Atmos. Solar Terr. Phys., 60, 1385-1402, 1998.

Rishbeth, H. and Roble, R. G., Cooling of the upper atmosphere by enhanced greenhouse gases - Modeling of thermospheric and ionospheric effects, Planet. Space. Sci., 40, 1011-1026, 1992.

Sergeenko, N. P. and Kuleshova, V. P., Long-term trends in ionospheric disturbances in the F2 region, Geomag. Aeronom. (in Russian), 35(5), 128-130, 1995.

Sergeenko, N. P. and Kuleshova, V. P., Climatic changes of the properties of disturbances in the ionosphere and upper atmosphere, Dokl. RAN (in Russian), 334 (4), 534-536, 1994.

Sergeenko, N. P. and Givishvili, G. V., On the problem of manyyear properties of ionospheric disturbances, Geomag. Aeronom. (in Russian), 37(2), 108-113, 1997.

Ulich, T. and Turunen, E., Evidence for long-term cooling of the upper atmosphere in ionospheric data, Geophys. Res. Lett., 24, 1103-1106, 1997.

Ulich, T., Karinen, A., and Turunen, E., Effects of solar variability seen in long-term EISCAT radar observations of the lower ionosphere, Paper presented at the Second IAGA/CMA Workshop on Solar Activity Forcing ofthe Middle Atmosphere, Prague, August 1997.

Upadhyay, H. M. and Mahajan, K. K., Atmospheric greenhouse effect and ionospheric trends, Geophys. Res. Lett. 25, 3375-3378, 1988 